\title{
Development of cost management and aided decision system for casting enterprises based on ERP
}

\author{
Hailin Zhang ${ }^{1}$
}

Shandong Jianzhu University, School of Computer Science and Technology, Jinan 250101, Shandong, China, 10086

\begin{abstract}
The present situation of production management and the application status of ERP in small and medium sized foundry enterpriseswere analyzed in this paper and a set of cost management and aided decision system based on ERP for foundry enterprises was developed. Application of the system can help managers regulate the production process, reduce production costs and improve economic efficiency.
\end{abstract}

\section{Introduction}

In the past two decades, the infrastructure of domestic foundry enterprises has been greatly developed. However, with the deepening of market economy and economic globalization, the focus of casting enterprises has shifted from the original single safety production to All-round development of economic efficiency as the center. Competitiveness of casting enterprises will be directly reflected in the safe production, low-cost operation and rapid response to customer needs.However, according to the study for foundry enterprises found that the domestic casting enterprises generally have poor information exchange, the data format between the enterprise sector is not uniform, the data is not concentrated, there is no decision support system, material planning is not strict and inventory control is not scientific and other questions[1-5].

Process flexible method of casting enterprise ERP was studied in literature[1]. The application status of China's foundry ERP wasstudiedand the application of HZERP was mainly introduced in Literature [2]. The cost accounting of various production processes was studiedin literature [3]. The construction of casting defect database was studiedin Document [4].The integration of foundry production and financial supply chain was studiedin literature [5].The advantages and disadvantages of the foundry enterprise ERP in the above documentswere comprehensively analyzed and the cost management and aided decision system for the foundry enterprise was developed in this paper.

\footnotetext{
${ }^{1}$ Corresponding author: lynn963@163.com
} 


\section{System requirememts analysis}

With the development of market economy, foundry enterprises are facing more and more intense competitive environment, ERP is being favored by all walks of lifebecause it has a richer function.

At present, the understanding of the principle of ERP of the domestic foundry industryis not enough, and the importance for ERP implementation is not high, many casting enterprises still believe that ERP implementation isthe installation of simple reportsoftware and purchase of computer equipment, this will lead to that ERPcannot play the desired effect.

The cost management and aided decision-making system of foundry enterprises based on ERP developed in this paper can solve these problems in a targeted way.

The system is divided into five subsystems, which are include casting parameter subsystem, production process subsystem, cost accounting subsystem, equipment management subsystem and system maintenance subsystem. System function block diagram is shown in Figure 1.

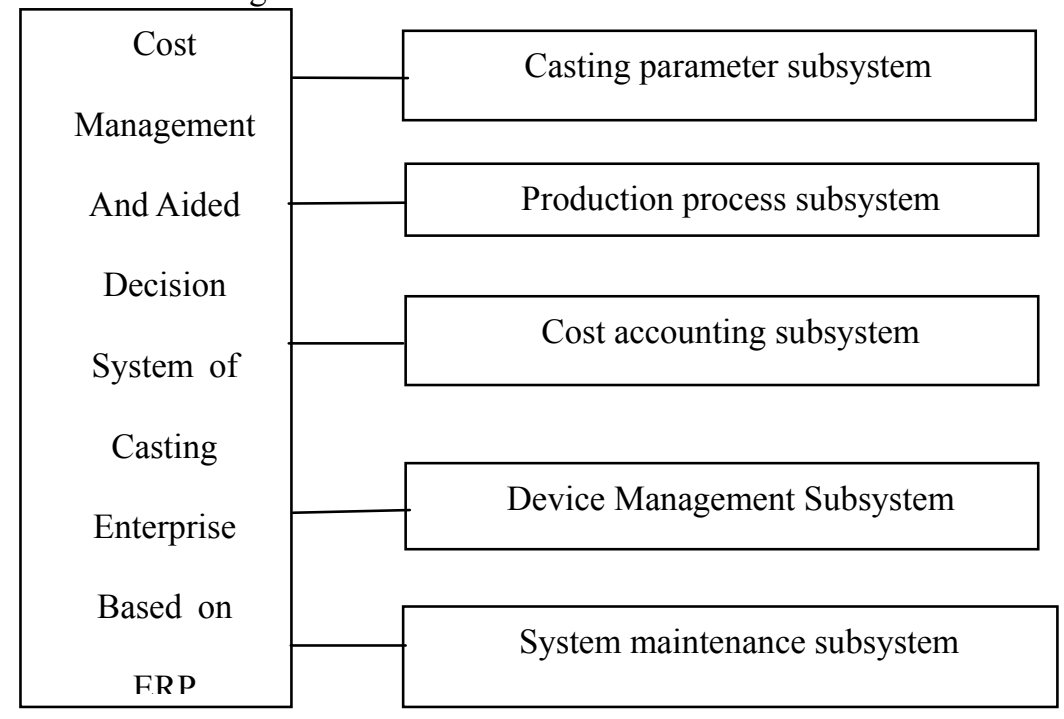

Fig. 1. System function module diagram

\section{Pringcples of cost calculation}

Cost is a comprehensive economic indicator; all aspects of work performance of business management can be directly or indirectly reflected in the cost, so the cost control is an important part of the work of the enterprise.

Enterprises through the cost of planning, control, supervision, assessment and analysis to promote the management of various departments, and constantly optimize the use of resources, and strive to reduce costs and improve economic efficiency.Enterprises will promote the management of various departments, constantly optimize the use of resources, strive to reduce costs and improve economic efficiency through the planning, control, supervision, assessment and analysis of cost.

Cost management is the core of the ERP system, the fundamental purpose of the enterprise selected ERP system is scientific reduction of operating costs and making decisions according to the actual data. 


\subsection{The cost type in ERP}

The cost accounting in the ERP system uses the standard cost system, which has standard costs, target costs and actual costs. As a tool for management control standard costcan simplify the cost accounting procedures, be conducive to cost analysis, and adjust business strategy in the face of rapidly changing market; target cost is the need for cost control; actual costs are used to reflect the actual production situation.

The system calculates the actual cost by calculating the production cost of each subsystem and carries out the cost budget and then find out the problems in the actual production to provide the data support for making the rational decision through comparing the cost of the actual cost and the forecast cost.

\subsection{Principles of cost calculation in ERP}

In ERP, the cost is calculated through the bill of materials BOM (Bill of Material). BOM is a complete, formal, structured list of components that lists the hierarchical membership and quantity relationships from raw materials to parts, components up to the end product.BOM is the basis for cost accounting, but also the basis for the preparation of material procurement and production planning. The cost calculation method in ERP is called the cost rolling method, which usually used to calculatethe standard cost and the actual cost.The BOM structure of a product is shown in Figure 2, which is a three-tier structure, the first layer is the final product A, the second layer is its direct component and the third layer is the direct subordinate partsof the second layer.The leaf nodes of the product tree are non-subdivided parts, standard parts or purchased parts.

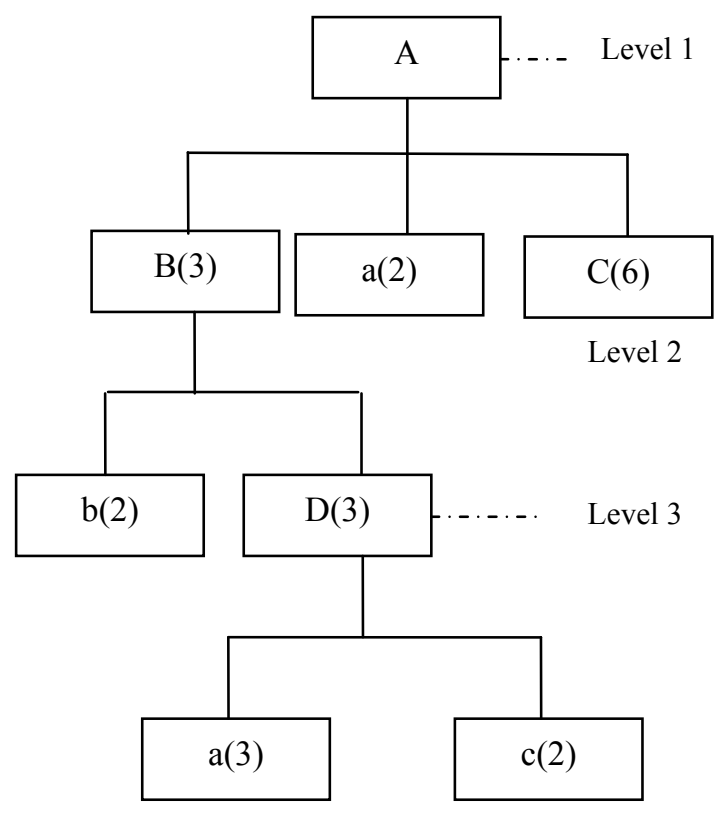

Fig.2. BOM structure diagram

According to the characteristics of the process of casting production, the step-by-step method in the cost calculation method is selected as the cost calculation method, that is, the actual cost calculation is carried out as the individual production module according to the order of the casting production process, and finally the cost is accumulated. 


\section{Implemation of the system}

The system was developedbased on Windows7 by the use of $\mathrm{C} \#$ as the development language, the use of Visual Studio 2015 as a development platform and the use of SQL Server 2015 as a back-end database. System design features are as follows:

ERP cost management was introduced into the casting production process. Casting material cost management was carried out by the use of advanced concepts of ERP cost management andcombination with the actual situation of casting production to provide accurate cost information for the cost of management and decision-making of enterprise.

Using the method of comparative analysis as the method of material cost analysis, qualitative analysis method was used as the method of casting material cost decision-making, which can provide a complete set of cost information management and decision-making system for casting materials for enterprises. So that enterprises can find the problem of the production, better control productions costs and improve business efficiency through comparing the predicted cost of materials with the actual cost.

\section{Application of the system}

After the system was developed, it was also adjusted according to the actual needs, and now has been stable operationfor some time. Then take the cost accounting system as an example to illustrate the application of the system.

The costing subsystem can find the problems in the production by comparing the cost and the actual cost reduce the production cost and improve the enterprise's efficiency by modifying the ratio of the raw materials or improving the production process.

The cost accounting subsystem is divided into three modules: raw material demand cost summary and cost analysis.

Among them, the raw material demand module is divided into two parts: raw material demand and raw material supply.

According to the production process, the cost summary module can record the productions cost of the various modules and calculate the final total cost starting from the sand production.

The total cost and the production costs of each module can be found when querying, which will help decision-makers to keep abreast of the entire production process dynamic information.

Table 1. Comparison of before and after the implementation of this system in Shandong Chang Lin

\begin{tabular}{|c|c|c|}
\hline business project & $\begin{array}{c}\text { before the implementation of the } \\
\text { system }\end{array}$ & $\begin{array}{c}\text { after the implementation } \\
\text { of the system }\end{array}$ \\
\hline $\begin{array}{c}\text { raw material } \\
\text { management }\end{array}$ & $\begin{array}{c}\text { the cost of business was affected } \\
\text { by price fluctuatingof scrap, coal } \\
\text { and other raw material }\end{array}$ & $\begin{array}{c}\text { reducing raw material } \\
\text { costsby the cost } \\
\text { accounting }\end{array}$ \\
\hline $\begin{array}{c}\text { production } \\
\text { management }\end{array}$ & $\begin{array}{c}\text { personal experience, easily lead } \\
\text { to inventory backlog }\end{array}$ & $\begin{array}{c}\text { make plans } \\
\text { scientifically ,reduce } \\
\text { inventory }\end{array}$ \\
\hline device & $\begin{array}{c}\text { maintenance,scrapping, } \\
\text { updatingand maintenance of } \\
\text { device was not timely }\end{array}$ & $\begin{array}{c}\text { timely maintenance of } \\
\text { equipment to improve } \\
\text { production efficiency }\end{array}$ \\
\hline
\end{tabular}

In accordance with the various labor departments of production process subsystems, cost analysis module can compare the actual cost and forecast coststo determine whether 
the production process and material ratio is to meet the requirements. If the requirements are met then proceed to the next step, if the requirements are not met, you need to find the cause of the problem, improve the process or material ratio, make it more perfect, and ultimately achieve the expected cost, achieve the purpose of cost control and supporting decision-making.

The system is often used in Shandong ChangLin Machinery Co., Ltdfor some time and has achieved good results, the specific comparison shown in Table 1 above.

\section{Conclusions}

The system has the friendly interfaceeasy to operate and has a stable operation in Shandong Province for some time. The system can help managers quickly and accurately understand the progress of real-time production, accurately calculate the cost and the total cost of the ministry, compare with the predicted cost, detect and correctthe various problems in the Ministry of Industry and achieve the purpose of reducing production costs.

\section{References}

1. Xiao-Wei FAN, Xiao-Yuan JI and Jian-Xin ZHOU.2016.Research on Process Flexibility Method and Application of ERPSystem to Foundry Enterprises. FOUNDRY.165,11(November,2016),1089-1094.

2. Jian-Xin ZHOU,Xiao-Yuan Ji and Dun-Ming Liao.2013.Research andapplication of ERP system for foundry enterprise. China Foundry.10,1(Janury,2013), 8-17.

3. Jing-Wen QIAO.2015.Analysis on Cost Analysis and Control Measures of Foundry Enterprises. Automation and Instrumentation,190(August,2015), 79-80.

4. Zeng-Li LI, Zhong-De SHAN and Ke-RuiLI.2017.Construction and Application of Casting Defects Database.FOUNDRY.66,2(February,2017), 150-154.

5. Ting-Yong Ming, Xiao-Yuan Ji and Jian-Xin Zhou.2016.A Feasibility Analysis of the Integrationand the Financial Supply Chain Systemof the Manufacturing Systemin the Foundry Enterprise.Special Casting and Nonferrous Alloys.36,6(June,2016), 594-597. 